\title{
EDUCAÇÃO AMBIENTAL NOS DOCUMENTOS NORTEADORES DA EDUCAÇÃO INFANTIL EM MANAUS (AM)
}

Agda Monteiro de Souza ${ }^{1}$

Resumo: Temos por objetivo evidenciar elementos da Educação Ambiental (EA) em documentos norteadores da educação infantil, a saber: Diretrizes Curriculares Nacionais para Educação Infantil e Proposta PedagógicoCurricular de Educação Infantil de Manaus. A metodologia é na abordagem qualitativa e fundamenta-se na análise documental. Explicitamos que a EA está presente tanto nas diretrizes nacionais quanto na proposta municipal. Em ambos os documentos se evidenciam elementos da EA, eles expressam práticas de educação e cuidados para formação integral da criança por meio de experiências proporcionadas a ela que promovam o cuidado, a preservação, o conhecimento da biodiversidade e da sustentabilidade da vida na terra.

Palavras-chave: Educação Ambiental; Educação Infantil; Currículo.

Abstract: Our goal is to show evidence for the elements of Environmental Education (EE) in documents guided by the preschool education followed by the National Curriculum Guidelines for Preschool Education and a PedagogicalCurricular Proposal for Preschool Education in Manaus. This has been done by a methodology of Qualitative Approach which is based on documental analysis. We make sure that the EE is present in both National Guidelines and Municipal Proposals. In both documents there are evidence of elements from EE, once they express practices of education and care for the entire formation of the children by means of experiences brought to them which promote the care, the preservation, the knowledge of biodiversity and the sustainability of life on earth.

Keywords: Environmental Education; Preschool Education; Curriculum. Link para o Lattes: http://lattes.cnpq.br/6601316236999557 


\section{Introdução}

Nesta pesquisa analisamos dois documentos que norteiam a educação infantil, evidenciando a Educação Ambiental contida neles. Um deles é de abrangência nacional e o outro municipal.

As Diretrizes Curriculares Nacionais para Educação Infantil (DCNEI) de 2010, oriunda do Parecer $n^{\circ}$ 20/2009 e Resolução $n^{\circ}$ 5/2009 de dimensão nacional, norteiam a elaboração de propostas pedagógico-curriculares para a educação das crianças de zero a cinco anos de idade em todo território brasileiro, garantindo não somente o trabalho pedagógico, mas também o sociopolítico, desde o início da educação básica (BRASIL, 2009a) e (BRASIL, 2009b, Art. 1ㅇ; Art. 7우).

O outro documento, de origem municipal, orienta o trabalho de creches e pré-escolas na cidade de Manaus, denominado de Proposta PedagógicoCurricular de Educação Infantil - PPCEI (MANAUS, 2016), cujo teor dá direcionamento aos trabalhos dos profissionais que lidam com a educação e cuidados das crianças menores de seis anos, e segundo a Secretaria Municipal de Educação - SEMED do município de Manaus, tal documento é fundamentado nas DCNEI (BRASIL, 2009b).

Contudo, para compreensão geral a respeito da EA contida nesses dois documentos, explicitaremos nos resultados e discussões alguns marcos internacional e brasileiro a respeito da EA.

Ressaltam Oliveira (2007) e Souza (2018) que a educação infantil está consolidada como um direito da criança, porém, em sua gênese, não era assim. As crianças eram deixadas por suas mães em instituições filantrópicas ou públicas enquanto estavam no trabalho. Nesse sentido, corroboram Silva, Pasuch e Silva (2012) e Oliveira (2007) quando afirmam que por muito tempo a caridade permeava o atendimento às crianças e essa concepção assistencial de educação infantil continua até os dias atuais, no trabalho de alguns profissionais por falta de formação profissional e fundamentação teórica.

Segundo Craidy e Kaercher (2001), citado por Souza (2018), o avanço das pesquisas para esse nível de educação contribuiu para se construir um novo olhar sobre a infância. As mudanças foram possíveis porque se passou a dar importância a esse momento específico do desenvolvimento humano e também se modificou na sociedade o modo de se pensar o que é ser criança, reconhecendo-a como sujeito histórico e social, com cultura própria, um ser em desenvolvimento, sempre aprendendo no percurso de sua fase geracional.

Dessa forma, mudanças em relação ao atendimento às crianças são implementadas, dentre algumas, citamos a Constituição Federal de 1988, o Estatuto da Criança e do Adolescentes - ECA de 1990, a Lei de Diretrizes e Bases da Educação Nacional (LDB) de 1996, as DCNEl e alterações, além de outros, garantindo o direito à inserção da criança de zero a cinco anos ao primeiro nível da educação básica, modificando também a formação dos profissionais da área da educação que trabalham com essa faixa etária.

revista brasileira educação ambiental 
Assim, o objetivo deste artigo é evidenciar elementos da Educação Ambiental nas DCNEI e na PPCEI, a partir de uma análise documental fundamentada na análise de conteúdo. A partir da leitura das DCNEI e da PPCEI depreende-se que ambas estão fundamentadas em pesquisas contemporâneas sobre a educação das crianças, e que o trabalho pedagógico deve estar articulado às experiências pautadas em saberes do contexto local, geral e científico, direcionando a formação integral da criança.

Em suma, a Educação Ambiental está presente no currículo da educação infantil, contudo, só produz efeito se o desenvolvimento curricular for realizado dentro de um contexto específico e sem antecipar conteúdos que serão trabalhados no ensino fundamental (BRASIL, 2010).

\section{Metodologia}

Primeiramente, realizamos um estudo bibliográfico sobre a gênese da Educação Ambiental com o objetivo de reunir ideias suficientes sobre os acordos internacionais para a implantação da Educação Ambiental a nível mundial. Posteriormente, realizamos uma revisão teórica sobre a Educação Ambiental brasileira, permitindo uma análise preliminar, qualitativa. Como relata Creswell (2010), que a pesquisa qualitativa é uma forma de investigação interpretativa, devido seus pesquisadores interpretarem o que enxergam, ouvem ou entendem de um fenômeno estudado.

Quanto à análise dos dados, foram referenciados pela análise de conteúdo, compreendida como um conjunto de procedimentos cujo objetivo é buscar sentido (s) de um documento (BARDIN, 2016). Para a autora, a análise de conteúdo é um conjunto de técnicas de análise das diversas formas de comunicações, cuja finalidade é realizar uma reflexão crítica sobre os dados coletados. Em concordância a isso, realizamos a análise documental de dois documentos que orientam os trabalhos pedagógicos na educação infantil e fundamentamos nos autores da nossa revisão de literatura. Além disso, observamos as fases de pré-análise, exploração do material, tratamento dos dados, inferência e intepretação, pontuadas por Bardin (Ibdem)).

\section{Resultados}

\section{Tecendo um diálogo sobre a trajetória da Educação Ambiental}

Implantada através de acordos governamentais internacionais, a EA é concebida na Política Nacional de Educação Ambiental (PNEA) sob a Lei 9795/99 (BRASIL, 1999) como sendo os processos por meio dos quais o indivíduo e a coletividade constroem valores sociais, conhecimentos, habilidades, atitudes e competências voltadas para a conservação do meio ambiente, bem de uso comum do povo, essencial à sadia qualidade de vida e sua sustentabilidade. 
Apesar da existência da Educação Ambiental em documentos oficiais de formas isoladas em alguns países, incluindo o Brasil, e da luta de movimentos ambientalistas anteriores aos anos de 1972, foi a partir da I Conferência Mundial sobre o Meio Ambiente Humano promovido pela Organização das Nações Unidas (ONU), nos anos 1972 em Estocolmo (amadurecidos posteriormente nos encontros realizados em Belgrado, Tbilisi e Brasil), que se teve os primeiros debates com os chefes de Estados onde se gerou a Declaração sobre Meio Ambiente Humano, conhecida como Declaração de Estocolmo de 1972, na qual se reconhece que tanto a geração presente quanto a futura deve ter direito a um ambiente sadio e com as mesmas oportunidades que as gerações anteriores.

$\mathrm{Na}$ referida declaração, considerada por alguns pesquisadores como o marco inicial para se debater a nível mundial sobre questões ambientais, há um preâmbulo com sete pontos e vinte e seis princípios. O princípio dezenove aborda ser indispensável um esforço para a educação em questões ambientais, tanto das gerações jovens quanto das adultas (DECLARAÇÃO DE ESTOCOLMO, 1972).

Ainda nessa conferência, foi produzido um Plano de Ação para o Meio Ambiente Humano com cento e nove recomendações. Na recomendação noventa e seis que versa sobre a EA, propõe-se à ONU o estabelecimento de um programa internacional de EA que fosse interdisciplinar em todos os níveis de ensino formal e também nos espaços educativos não formais, assim como aos cidadãos em geral, com o objetivo de conscientizar quanto aos cuidados do meio ambiente. Assim, nos anos 1975 a ONU cria o Programa Internacional de Educação Ambiental - PIEA (DECLARAÇÃO DE ESTOCOLMO, 1972; CARTA DE BELGRADO, 1975).

No encontro seguinte, denominado de Seminário Internacional de Educação Ambiental, realizado em Belgrado, nos anos 1975, gerou-se a Carta de Belgrado que aponta as consequências do crescimento econômico a partir das explorações humanas e ambientais, além de tecer alguns pontos sobre as desigualdades entre grupos sociais e nações. A referida carta versa também sobre a erradicação da pobreza, da fome, do analfabetismo, da poluição, da exploração e dominação humana e ratifica que essas questões não podem ser tratadas de forma fragmentadas como vinha ocorrendo (DIAS et al, 1998; CARTA DE BELGRADO, 1975).

A carta também sugere à sociedade uma nova concepção de desenvolvimento econômico em harmonia com o ambiente e a redução dos danos causados ao mesmo, baseada na "Nova Ordem Econômica Internacional", isto é, nos acordos oficialmente estabelecidos nos encontros entre os governos internacionais. Por conta disso, propõe reforma nos sistemas educacionais com início da EA desde a educação básica (da educação infantil ao ensino médio) até a superior, além da formação de professores e de profissionais da educação, com vista a alcançar as metas mundiais estabelecidas para que seus resultados sejam refletidos no comportamento dos

revista brasileira educação ambiental 
sujeitos, para melhoria da qualidade do ambiente para o indivíduo e a coletividade (Ibdem, Ibdem).

Encontram-se os direcionamentos da Carta de Belgrado explicitados no artigo 225 da Constituição Federal de 1988 e na Lei 9795/1999 que institui a Política Nacional de Educação Ambiental em todo território brasileiro (DIAS et al, 1998).

Há também as contribuições do terceiro encontro dos governos mundiais denominado de I Conferência Intergovernamental sobre Educação Ambiental, realizada em Tbilisi nos anos de 1977. Desse encontro emergiu a Declaração de Tbilisi com quarenta e uma recomendações, cujos direcionamentos estão explicitados na Lei 9795/1999 mencionada anteriormente. Segundo Dias et al (1998, p. 30) a "referência para quem quer fazer Educação Ambiental está nos documentos finais" do encontro de Tbilisi, pois "foi deste encontro que saíram as definições, os objetivos, os princípios e as estratégias para a Educação Ambiental, que até hoje são adotados em todo o mundo". Daí o referido encontro ficar conhecido como um grande marco da EA no mundo inteiro.

A primeira recomendação da Declaração de Tbilisi explicita que, apesar dos aspectos biológicos e físicos constituírem a base natural do meio humano, as dimensões socioculturais, econômicas e os valores éticos definem as orientações com os quais o ser humano poderá compreender e melhor utilizar os recursos oferecidos pela natureza, para satisfazer as suas necessidades básicas sem esgotá-la. Destaca Brasil (2018, p. 15) que no referido documento "estão estabelecidos finalidades, objetivos, princípios e estratégias para a promoção da Educação Ambiental". E na terceira recomendação que se atribui à escola "um papel determinante no conjunto da Educação Ambiental", pois é por meio dela que se pode transformar progressivamente atitudes e comportamentos para que todos tenham consciência de suas responsabilidades, "contribuindo para a busca de uma nova ética baseada no respeito pela natureza, no respeito pelo homem e sua dignidade e no respeito pelo futuro, bem como na exigência de uma qualidade de vida acessível a todos" (DIAS et al, 1998, p. 33). Afirmam, ainda, os autores (p. 34) que a EA tem suas grandes linhas de orientações no encontro de Tbilisi, a partir destas orientações "traçam-se as prioridades nacionais, regionais e locais; desenhamse as suas estratégias e recursos instrucionais que deverão ser utilizados".

Ainda nessa retrospectiva histórica, a II Conferência Mundial para o Meio Ambiente e Desenvolvimento realizada no Brasil no município do Rio de Janeiro nos anos 1992, conhecida como Rio-92, Eco-92 ou Cúpula da Terra, reuniu chefes de Estados para debater e decidir medidas com fins de minimizar a crise ambiental e suas problemáticas. Segundo os documentos, foi nessa conferência que se admitiu a necessidade de conciliar desenvolvimento socioeconômico com os ativos disponíveis na natureza. Assim, o termo desenvolvimento sustentável foi oficializado (DIAS et al, 1998). 
Dessa conferência alguns documentos oficiais foram produzidos, entretanto, destacamos a Carta Brasileira de Educação Ambiental e a Agenda 21. A Carta, afirma Brasil (2018, p. 16), "dentre outras coisas, reconhece a Educação Ambiental como importante meio para viabilizar a sustentabilidade como estratégia de sobrevivência e melhoria de qualidade de vida humana". $\mathrm{Na}$ Agenda 21 é reforçado que para se estabelecer a melhoria da qualidade de vida no planeta, não basta apenas ações governamentais ou iniciativas do setor privado, é necessário o envolvimento da sociedade civil (DIAS et al, 1998).

Salientamos que ocorreram outros encontros entre os governos mundiais, a sociedade civil, especialistas e poder público para tratar das questões ambientais após a Rio-92, tais como a Conferência das Nações Unidas sobre Ambiente e Desenvolvimento Sustentável em Joanesburgo, nos anos 2002, chamada Rio+10, onde os países revisaram as metas da Agenda 21 e se concentraram em áreas carentes, com planos de ação global que conciliasse desenvolvimento e preservação ambiental. Também ocorreu no Brasil, em 2012, a III Conferência Internacional sobre Meio Ambiente e Desenvolvimento Sustentável, chamada Rio+20, onde revisaram as metas alcançadas e as que precisariam de apoio para se materializar.

Dessa forma, explicitamos momentos históricos que consolidou a EA no Brasil e no mundo. Dos acordos internacionais que originaram documentos oficiais no Brasil, relacionamos: o artigo 225 da Constituição Federal de 1988; o artigo 26 da LDB Lei 9394/96 que direciona aos temas transversais; os Parâmetros Curriculares Nacionais em seu caderno tema transversal Meio Ambiente e Saúde; as Diretrizes Curriculares Nacionais para a Educação Ambiental; a Política Nacional de Educação Ambiental (PNEA) e o Programa Nacional de Educação Ambiental (PRONEA); a Agenda 21 Brasileira; a Política de Educação Ambiental do Amazonas; as Agendas Ambientais Municipais; e a Proposta Pedagógico-Curricular dos estados e municípios, incluindo a Proposta Pedagógico-Curriculares de Educação Infantil de Manaus.

Sendo nossa pesquisa voltada à educação infantil, destacamos dos documentos oficiais supracitados as Diretrizes Curriculares Nacionais para a Educação infantil e a Proposta Pedagógico-curriculares de Educação Infantil. O primeiro é um direcionamento nacional e o outro é municipal, ambos abordaremos na sequência.

\section{A Educação Ambiental nas diretrizes curriculares nacionais para educação infantil}

Afirma Rosemberg (2003) que a educação infantil no Brasil é caracterizada em três fases. Na primeira, a preocupação era voltada para compensar as carências infantis, como os cuidados com alimentação, higiene e integridade física, pouco se valorizava o desenvolvimento intelectual, esta era voltada às camadas populares conforme os cânones da Organização das Nações Unidas para a Educação Ciência e Cultura (UNICEF) e do Fundo das 
Nações Unidas para a Infância (UNESCO), idealizada para os países subdesenvolvidos.

$\mathrm{Na}$ segunda, a autora afirma que se inicia com a reabertura política após o regime militar e com a participação dos movimentos sociais que se mobilizaram em prol da constituinte, cujos resultados em relação à educação infantil foi a inclusão deste nível de educação na Constituição Federal de 1988 e o reconhecimento da criança como detentora de direitos, além da implementação da Política Nacional de Educação Infantil em 1994 e da criação do Estatuto da Criança e do Adolescente em 1990.

A última fase diz respeito ao momento atual. É nessa fase da história que foi implementada a Lei de Diretrizes e Bases da Educação Nacional (LDBEN) em 1996; os Referenciais Curriculares Nacionais para a Educação Infantil (RCNEI) em 1998; as Diretrizes Curriculares Nacionais para a Educação Infantil (DCNEI) que teve sua primeira versão em 1999 com revisão em 2009; e o Plano Nacional de Educação (PNE) de 2001-2010, que se encontra atualmente em sua segunda versão que vai de 2014-2024.

Assim, esta pesquisa considera as DCNEI (Brasil, 2010) para discussão neste texto por ter sido revisada por meio do Parecer $n^{\circ}$ 20/2009 (BRASIL, 2009a) e Resolução $n^{\circ}$ 05/2009 (BRASIL, 2009b), dando direcionamento à organização das propostas pedagógicas para a educação infantil em todo território nacional. Segundo Brasil (2010, p. 7), tal conquista teve "ampla participação dos movimentos comunitários, dos movimentos de mulheres, dos movimentos de trabalhadores, dos movimentos de redemocratização do país, além, [...] dos próprios profissionais da educação".

As DCNEl orientam práticas junto às crianças menores de seis anos como forma de garantir a continuidade no processo de aprendizagem e desenvolvimento delas, sem antecipação de conteúdos que serão trabalhados no ensino fundamental. Enquanto os RCNEI (Brasil, 1998), segundo Farias e Palhares (2003), apresentaram desvios quanto ao trabalho pedagógico a ser desenvolvido com as crianças. Para as autoras, os RCNEI visam a preparação escolar da criança para o ingresso no ensino fundamental, além de sua proposta pedagógica não ter sido aberta à participação da sociedade civil organizada.

Portanto, as DCNEI (Brasil, 2009b) em seu artigo 5ำ define educação infantil como a primeira etapa da educação básica, devendo ser oferecida em creches e pré-escolas, em espaços não domésticos, isto é, em estabelecimentos educacionais públicos ou privados. Dessa forma, a educação infantil deixa de ser um direito meramente assistencial à mãe trabalhadora e passa a ser um direito da criança como cidadã, em ambientes próprios e com profissionais qualificados.

No artigo $3^{\circ}$ o currículo é estabelecido como um conjunto de práticas que articulam as experiências e os saberes das crianças com os conhecimentos que fazem parte do patrimônio cultural, artístico, ambiental, 
científico e tecnológico, promovendo o desenvolvimento integral da criança. Destacamos neste artigo que a EA deve estar no conjunto de práticas pedagógicas que devem ser proporcionadas aos pequenos, entrelaçadas aos saberes sistematizados pela sociedade e aos saberes que trazem consigo visando o pleno desenvolvimento delas.

Corrobora Capra (2006, p. 149) ao falar da necessidade de se educar as crianças para um mundo sustentável, tendo em vista que um grande quantitativo delas consegue identificar os mais variados tipos de produtos industrializados, no entanto, não sabem dizer ou identificar nomes de plantas e animais da sua região. Por isso, afirma ele, é necessário que o currículo seja construído com base no próprio lugar da aprendizagem para poder envolver "a sua geografia, a sua história, a cultura das comunidades do entorno [...]" (Ibdem, p. 19).

Afirma Carvalho (2011, p. 51) que a EA "surge da preocupação da sociedade com o futuro da vida e com a qualidade da existência das presentes e futuras gerações", daí a necessidade de se construir novas maneiras dos grupos sociais se relacionarem com o meio ambiente, explica ela. Nesse sentido, depreende-se a necessidade de a EA iniciar-se desde a mais tenra idade, também afirmado por CAPRA (2006).

Explicita o artigo 4ำ que as propostas pedagógicas deverão considerar a criança o centro do planejamento curricular, como sujeito histórico e de direitos e, nas interações, relações e práticas cotidianas que vivencia, constrói sua identidade pessoal e coletiva, brinca, imagina, fantasia, deseja, aprende, observa, experimenta, narra, questiona e constrói sentidos sobre a natureza e a sociedade. Este artigo se relaciona ao que afirma Capra (2006) a respeito de que uma horta escolar passa a ser não apenas um espaço de plantação de alimentos livres de veneno, mas o local onde se pode aprender os ciclos e fluxos dos ecossistemas, onde se observa a cadeia alimentar na natureza, o que seja resíduo de uma espécie é alimento para outra, enfim, para dirimir ou aguçar a curiosidade das crianças, completa o autor.

Esse exemplo acima apresentado pelo pesquisador é uma forma de se extrair do artigo 4ำ que é no trabalho docente cotidiano que a criança vivencia, observa, experimenta e questiona, ela constrói sentidos sobre a natureza, podendo interferir de forma positiva sobre ela, ao rever seus próprios valores. Além disso, a EA na perspectiva da observação, indagação e relação com a natureza, oferece elementos para a construção de conhecimentos socioambientais sólidos e não mero espaço de se praticar boas intenções, boas práticas ambientais ou, ainda, bons comportamentos ambientais (CARVALHO, 2011), contribui também com os direcionamentos das DCNEI (2009b) sobre o desenvolvimento integral da criança.

No inciso I do artigo 6ํㅡㄹ alguns princípios devem ser observados nas propostas pedagógicas para as crianças, como o "respeito ao bem comum, ao meio ambiente" (BRASIL, 2009b). O termo "bem comum" relacionado ao meio ambiente explicitado neste inciso está descrito na PNEA (BRASIL, 1999) como

revista brasileira educação ambiental 
sendo os processos pelos quais as crianças, neste caso, por meio de intervenção pedagógica, constroem valores sociais, conhecimentos, habilidades, atitudes e competências voltadas para a conservação do meio ambiente e a sustentabilidade, essenciais para a qualidade de vida.

Há também o inciso $\mathrm{V}$ do artigo $7^{\circ}$ onde se estabelece que a proposta pedagógica das instituições deve garantir sua função sociopolítica e pedagógica. Afirma o inciso que se faz necessário oferecer condições para que as crianças usufruam seus direitos civis e sociais e um deles é a formação da criança cidadã comprometida com a sustentabilidade do planeta, além do rompimento de relações de dominação socioeconômica, étnico-racial, regional, linguística, religiosa, dentre outras.

Além disso, o parágrafo $3^{\circ}$ do artigo $8^{\circ}$ visa garantir a manutenção das práticas ambientalmente saudáveis que trazem consigo as crianças, filhos (as) de agricultores familiares, extrativistas, pescadores artesanais, ribeirinhos, assentados e acampados da reforma agrária, quilombolas, caiçaras e povos da floresta. Complementando, o inciso IV do mesmo parágrafo reafirma que se deve valorizar e evidenciar os sabres dessas populações na produção de conhecimentos sobre o mundo e sobre o ambiente natural (BRASIL, 2009b).

Esses trechos expressam a participação das crianças com os conhecimentos tradicionais que trazem consigo e que se ampliam a partir dos saberes e conhecimentos de diferentes áreas, visando a ampliação cognitiva e de mundo dela. Envolver o (a) aprendiz como sujeito ativo em seu processo formativo é característica da Educação Ambiental emancipadora, Educação Ambiental do pensamento crítico, superando a lógica da educação tradicional (CARVALHO, 2004). Segundo a pesquisadora, a educação crítica tem suas raízes nos ideários democráticos e emancipatórios, oriundos da educação popular que rompe com a visão repassadora de conhecimentos.

Por fim, no artigo 9 incisos VIII e X (BRASIL, 2009b, p. 4) no que tange as práticas pedagógicas dos (as) docentes denominadas de experiências, destacamos os seguintes elementos da Educação Ambiental:

VIII - incentivem a curiosidade, a exploração, o encantamento, o questionamento, a indagação e o conhecimento das crianças em relação ao mundo físico e social, ao tempo e à natureza;

X - promovam a interação, o cuidado, a preservação e o conhecimento da biodiversidade e da sustentabilidade da vida na Terra, assim como o não desperdício dos recursos naturais. 
Corrobora Carvalho (2004, p. 21) que educar os sujeitos ambientalmente é levá-los a compreensão dos problemas socioambientais em suas múltiplas dimensões, sejam elas geográficas, históricas, biológicas e sociais, além de considerar "o ambiente como o conjunto das interrelações que se estabelecem entre o mundo natural e o mundo social, mediado por saberes locais e tradicionais, além dos saberes científicos" construídos socialmente.

Como evidenciamos, as DCNEI explicitam elementos para ações pedagógicas em Educação Ambiental na educação infantil. Desde sua concepção de currículo no artigo $3^{\circ}$ até as práticas pedagógicas no artigo $9^{\circ}$ da referida diretriz, encontra-se explicitamente os direcionamentos em EA, dos quais damos destaque ao inciso $X$ que afirma que as práticas dos docentes devem garantir às crianças experiências que "promovam a interação, 0 cuidado, a preservação e o conhecimento da biodiversidade e da sustentabilidade da vida na Terra, assim como o não desperdício dos recursos naturais" (BRASIL, 2009b, p. 4).

Feito essa exposição, averiguamos as orientações em Educação Ambiental na proposta pedagógica da SEMED Manaus.

\section{O que diz a proposta pedagógico-curricular da educação infantil da secretaria municipal de educação de Manaus a respeito da Educação Ambiental}

O texto de apresentação da PPCEI da SEMED Manaus afirma que o objetivo da proposta é "subsidiar os profissionais envolvidos, bem como interagir com a comunidade escolar e local da cidade de Manaus sobre o desenvolvimento de saberes e práticas específicas à educação da criança" (MANAUS, 2016, p.7). Também afirma que tem como base os documentos oficiais do MEC, Pareceres e Resoluções da Câmara de Educação Básica do Conselho Nacional de Educação, assim como os textos legais do Conselho Municipal de Educação de Manaus e que estão fundamentados em teorias produzidas cientificamente sobre a infância e o desenvolvimento da criança.

Destacamos ainda no texto de apresentação que a comissão organizadora reitera que houve a participação dos docentes, dos pedagogos, dos gestores, da comunidade e das próprias crianças na construção da proposta. Para isso, foi aplicado instrumentos de escuta pedagógica organizados pela equipe de assessores da própria Secretaria Municipal para este fim (Ibdem, Ibdem).

A proposta pedagógica contém 119 páginas e traz direcionamentos aos profissionais atuantes nas creches e nas pré-escolas do município. Como o objetivo da nossa pesquisa é a Educação Ambiental no espaço pré-escolar, então nos deslocaremos ao item 9 do referido documento cujo tema é "Os eixos norteadores do trabalho pedagógico na educação infantil" (MANAUS, 2016, p. 49). 
Sob orientação das DCNEI, a PPCEI da SEMED Manaus trabalha as doze experiências sugeridas no direcionamento nacional, contudo, mesmo sendo uma orientação, descreve como tais experiências devem se materializar no cotidiano com os pequenos.

Assim, a PPCEI da SEMED Manaus apresenta no item 9.8 em sua experiência número 8 o que está disposto no inciso VIII do artigo 9ำ das DCNEI que diz "garantir experiências que incentivem a curiosidade, a exploração, 0 encantamento, o questionamento, a indagação e o conhecimento das crianças em relação ao mundo físico e social, ao tempo e à natureza" (MANAUS, 2016, p. 62-63; BRASIL 2009b, p. 4) e orienta na prática como deve ser feito:

O professor conduzirá brincadeiras ao redor da instituição incentivando as crianças a colher pedrinhas, galhos, frutos, folhas e flores e, em seguida, trabalhará as diferentes formas e maneiras de criar, recriar e explorar a natureza [...] produzindo então, em um objeto de arte, uma demonstração de carinho e cuidado com a natureza.

O professor deve dispor às crianças no momento do jogo, noções de sequência, regras, perdas e ganhos. Deve também, incentivar as crianças a produzir atividades utilizando elementos enriquecedores da natureza como folhas, flores, galhos, pedras, areia etc. nas suas produções.

O tempo ontem, hoje e amanhã faz parte do dia a dia da criança e de sua rotina, assim, toda atividade da turma deve constar em um portfólio para [...] demonstrações [...] de seu desenvolvimento. (MANAUS, 2016, p. 62-63)

$\mathrm{Na}$ proposta da SEMED Manaus no item 9.10 em sua experiência número 10 , também encontramos a mesma sugestão de práticas disposta no inciso X do artigo 9o das DCNEI que diz "promovam a interação, o cuidado, a preservação e o conhecimento da biodiversidade e da sustentabilidade da vida na Terra, assim como o não desperdício dos recursos naturais" (MANAUS, 2016, p. 64-65; BRASIL, 2009b, p. 4) e orienta na prática que:

As experiências sugeridas para o trabalho com as crianças nas unidades de Ensino de Educação Infantil são aquelas que permitam uma aproximação e exploração do meio natural, tais como: Brincadeiras com areia; Ouvir os sons da natureza; Brincadeiras ao ar livre; Escultura com argila; Construção de hortas; Coleta seletiva de lixo; Exploração do espaço externo da escola e muitas outras experiências que permitam às crianças explorar o ambiente. 
contudo, afirma Carvalho (2004, p. 27) que os professores, por falta de formação profissional adequada, têm promovido uma Educação Ambiental que privilegia "o aspecto cognitivo do processo pedagógico, acreditando que transmitindo o conhecimento correto fará com que o indivíduo compreenda a problemática ambiental" e, dessa forma, transforma seu comportamento e a sociedade.

Para Ruscheinsky (2004, p. 53) se ambiciona ultrapassar a adesão a projetos de reciclagem de detritos, de acondicionamento adequado do lixo ou da preservação de áreas verdes. Afirma o pesquisador que "para tal intuito há de se investir em mudanças culturais que afetam a mentalidade, e o comportamento no modo de pensar e agir".

\section{Considerações}

A partir da revisão de leitura das Diretrizes Curriculares Nacionais para a Educação Infantil evidenciam-se ao longo de seus treze artigos orientações para a Educação Ambiental na educação infantil tanto na creche quanto na préescola. No processo de leitura da referida diretriz, identifica-se que a ação pedagógica está articulada com as experiências que proporcionam o contato da criança tanto com os saberes sistematizados pela humanidade quanto pelos sabres que os pequenos trazem consigo do seu contexto social. Assim, em especial os artigos $3^{\circ}, 4^{\circ} 6^{\circ}, 7^{\circ}, 8^{\circ}$ e $9^{\circ}$ trazem direcionamentos específicos para se trabalhar a Educação Ambiental. Citamos, por exemplo, o inciso $\mathrm{X}$ do artigo 9o que descreve que as práticas pedagógicas devem garantir experiências que "promovam a interação, o cuidado, a preservação e o conhecimento da biodiversidade e da sustentabilidade da vida na Terra, assim como o não desperdício dos recursos naturais".

Oriunda das diretrizes nacionais, a Proposta Pedagógico-Curricular de Educação Infantil do município de Manaus também evidencia direcionamentos para ações pedagógicas, em especial as proposições nos campos de experiências 8 e 10 descritas no referido documento. Mencionamos, por exemplo, sugestões de experiências que devem ser realizadas na área externa da sala de referência conduzindo os pequenos a "colher pedrinhas, galhos, frutos, folhas, flores" para que elas possam criar, recriar e explorar a natureza por meio das artes, levando-as a ter carinho e cuidado com a natureza. Outra sugestão é levar as crianças à exploração do meio natural tais como brincadeiras com areia, ouvir sons da natureza, construção de hortas e coleta seletiva de lixo na escola.

Inferimos que a Educação Ambiental está prescrita nos documentos nacionais e locais que norteiam as ações pedagógicas de cuidados e educação das crianças, contudo, alerta Carvalho (2004) que os docentes, por falta de formação profissional adequada, não venham promover apenas uma Educação Ambiental que se privilegia o aspecto cognitivo do aprendiz, acreditando que transmitindo o conhecimento correto fará com que o indivíduo compreenda a crise ambiental e, dessa forma, transforme seu comportamento e a sociedade.

revista brasileira educação ambiental 
Corrobora Ruscheinsky (2004) que é necessário investir em mudanças culturais que afetam a mentalidade e o comportamento no modo de pensar e agir.

\section{Agradecimentos}

Agradecemos a Fundação de Amparo à Pesquisa do Estado do Amazonas (FAPEAM), pelo apoio financeiro à pesquisa.

\section{Referências}

BARDIN, L. Análise de conteúdo. 3. reimp. ed. 2016. São Paulo: Edições 70, 2016. (Tradução Luís Antero Reto e Augusto Pinheiro).

BRASIL. Ministério da Educação e do Desporto, Secretaria de Educação Fundamental. Referencial Curricular Nacional para a Educação Infantil RCNEI. Brasília: DF, MEC/SEF, 1998.

BRASIL. Lei no 9.795, de 27 de abril de 1999, Dispõe sobre a Educação Ambiental, institui a Política Nacional de Educação Ambiental e dá outras providências. Brasília, DF: Presidência da República (Casa Civil), 1999.

BRASIL. Diretrizes curriculares nacionais para a educação infantil DCNEI. Secretaria de Educação Básica. Brasília: MEC, SEB, 2010.

BRASIL. Ministério da Educação. Conselho Nacional de Educação. Parecer $\mathbf{n}^{\circ}$ 20, de 11 de novembro de 2009. Revisão das Diretrizes Curriculares para a Educação infantil. Brasília: MEC, CNE, 2009a.

BRASIL. Ministério da Educação. Conselho Nacional de Educação. Resolução $\mathbf{n}^{\circ}$ 05, de 17 de dezembro de 2009. Fixa as Diretrizes Curriculares para a Educação infantil. Brasília: MEC, CNE, 2009b.

BRASIL. Ministério do Meio Ambiente - MMA. Ministério da Educação - MEC. Educação Ambiental por um Brasil sustentável: PRONEA, marcos legais e normativos [recurso eletrônico]. Brasília, DF: MMA, 2018.

CARTA DE BELGRADO - 1975. Disponível em: http://www.fzb.rs.gov.br/upload/20130508155641carta de belgrado.pdf.Acesso em: 19 mar. 2020.

CARVALHO, I.C.M. Educação Ambiental crítica: nomes e endereçamentos da educação. In: LAYRARGUES, P.P. (Coord.). Identidades da Educação Ambiental brasileira. Brasília: Ministério do Meio Ambiente, 2004.

CARVALHO, I.C.M. Educação ambiental: a formação do sujeito ecológico. 5. ed. São Paulo: Cortez, 2011.

CAPRA, F. Alfabetização ecológica: educação das crianças para um mundo sustentável. Tradução Carmen Fischer. São Paulo. Cultrix, 2006.

CRAIDY, C. M.; KAERCHER, G. E. P. S. Educação infantil: pra quê te quero? Porto Alegre: Artmed, 2001. 
CRESWELL, J.W. Projeto de pesquisa: métodos qualitativo, quantitativo e misto. 3. ed. Porto Alegre: Artmed, 2010.

DECLARAÇÃO DE ESTOCOLMO SOBRE O AMBIENTE HUMANO - 1972. Disponível em: http://www.direitoshumanos.usp.br/index.php/MeioAmbiente/declaracao-de-estocolmo-sobre-o-ambiente-humano.html. Acesso em: 19 mar. 2020.

DECLARAÇÃO DE TBILISI - 1977. Disponível em: https://moodle.unesp.br/ava/pluginfile.php/28831/mod resource/content/1/UNE SCO-TBILISI.pdf. Acesso em: 19 mar. 2020.

DIAS, G.F. et al. A Implantação da Educação Ambiental no Brasil. Publicação de responsabilidade da Coordenação de Educação Ambiental do Ministério da Educação e do Desporto, Brasília - DF, 1998, 166 páginas.

FARIA, A. L. G. de; PALHARES, M. S. (Orgs.). Educação infantil pós-LDB: rumos e desafios. 4. ed. Campinas: Autores associados, 2003.

MANAUS. Secretaria Municipal de Educação. Divisão de Educação Infantil. Proposta pedagógico-curricular de educação infantil. Manaus: SEMED/DEI, 2016.

OLIVEIRA, Z. M. R. O currículo na educação infantil: o que propõem as novas diretrizes nacionais?. Agosto, 2010. Disponível em: http://portal.mec.gov.br/docman/dezembro-2010-pdf/7153-2-1-curriculo educacao-infantil-zilma-moraes/file. Acesso em: 16 mar. 2020.

OLIVEIRA, Z. M. R. Educação Infantil: fundamentos e métodos. 2. ed. São Paulo: Cortez, 2007.

ROSEMBERG, F. Panorama da educação infantil brasileira contemporânea. In: Anais do simpósio educação infantil: construindo o presente. Brasília. Ed. Brasileira pela UNESCO, 2003. Disponível em: http://www.dominiopublico.gov.br/download/texto/ue000311.pdf. Consultado em: 22 abril 2020.

RUSCHEINSKY, A. Atores sociais e meio ambiente: a mediação da ecopedagogia. In: LAYRARGUES, P.P. (Coord.). Identidades da Educação Ambiental brasileira. Brasília: Ministério do Meio Ambiente, 2004.

SILVA, A.P.S.; PASUCH, J.; SILVA, J.B. Educação Infantil do Campo. São Paulo: Cortez, 2012

SOUZA, A.M. O currículo da educação infantil: um estudo em escola municipal no assentamento tarumã mirim. Dissertação (Mestrado em Educação em Ciências na Amazônia) - Universidade do Estado do Amazonas - UEA, 170 f. Manaus: UEA, 2018. Disponível em: $<$ http://www.pos.uea.edu.br/data/area/titulado/download/90-1.pdf. Consultado em: 18 mar. 2020. 